\title{
RESTLESS LEGS SYNDROME INDUCED BY SPINAL ANESTHESIA WITH PRILOCAINE, A CASE-SERIES
}

\author{
M. Van Diem ${ }^{1}$, M. Fenten ${ }^{1}$, J. Bruhn ${ }^{1}$, G. van Geffen ${ }^{1}$. \\ ${ }^{1}$ Radboud University Medical Center, Department of Anesthesiology, \\ Nijmegen, The Netherlands.
}

\section{Background and Aims}

Restless leg syndrome (RLS) is the most common movement disorder, which is characterized by an irresistible urge to move the legs in rest. The mechanism behind this syndrome is not yet completely understood. It can occur secondary to other medical conditions, such as iron deficiency, renal failure, pregnancy, venous insufficiency, acute spinal cord lesions, stroke and many more. There seems to be involvement of the dopaminergic system. RLS has been described during and after spinal anesthesia using bupivacaïne en lidocaine, the mechanism behind these symptoms is not yet understood.

\section{Methods}

In this case series we present three patients who experienced restless legs during spinal anesthesia using hyperbaric prilocaine. None of our three patients received anti-dopaminergic drugs, or suffered from any of the medical conditions associated with an increased risk for RLS.

\section{Results}

In these three patients we did not treat the restless legs, but provided sedation in order to comfort and to overcome the discomforting symptoms. Moreover, we reassured our patients that the symptoms would diminish when the spinal anesthesia would wear off, which was the case in all patients.

\section{Conclusions}

This is the first case series to describe RLS symptoms during spinal anesthesia with hyperbaric prilocaïne. The mechanism is unclear, but restless legs have been described before after intrathecal injection of lidocaine and bupivacaine. The restless legs symptoms disappear when the motor block wears off.

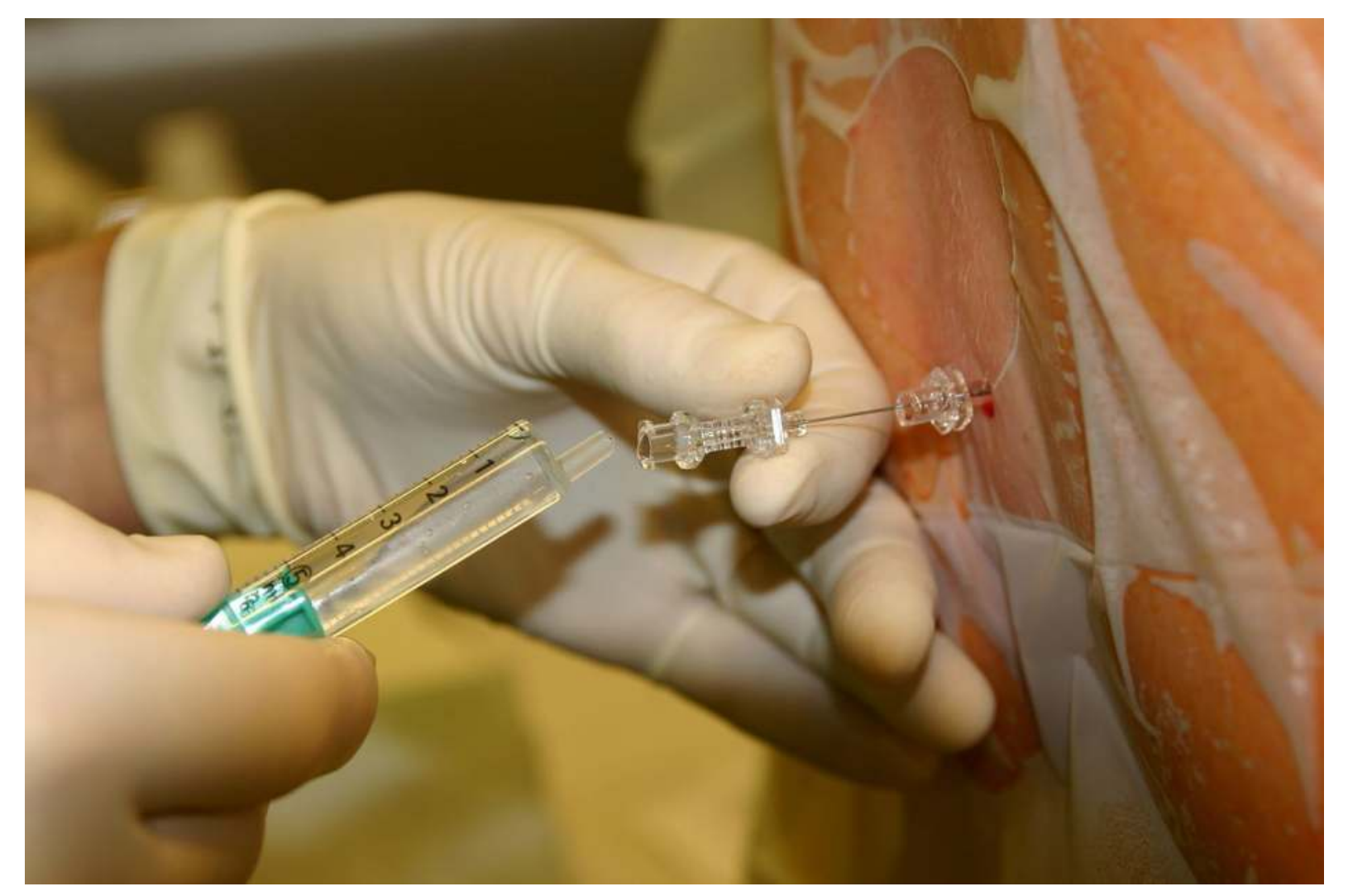

